\title{
Educação de Jovens e Adultos em um Cenário de Mudança: entre a indignação e a esperança
}

\author{
Educación de Jóvenes y Adultos en un Escenario de Cambio: entre la \\ indignación y la esperanza
}
Youth and Adult Education in a Setting of Change: between indignation and hope

\author{
Daiane Ferreira Ferreira ${ }^{1}$ \\ Elaine Corrêa Pereira ${ }^{2}$ \\ Vilmar Alves Pereira ${ }^{3}$
}

\begin{abstract}
Resumo
Este estudo traz um recorte da Dissertação "O Horizonte da Educação de Jovens e Adultos Enquanto Instrumento de Emancipação da Classe Trabalhadora: Reflexões sobre Educação Trabalho e Ensino Médio" tem como propósito dialogar sobre a Educação de Jovens e Adultos - EJA, como uma modalidade importante no que tange a democratização e o direito a educação. Ciente de que, nossa sociedade vem caminhando na contra marcha do combate as desigualdades sociais, principalmente no que se refere à oferta do ensino de EJA e as políticas de permanências. Neste sentido, buscamos fazer uma pesquisa sobre o cenário da EJA no município de Rio Grande e as políticas públicas estabelecidas. Ressaltamos que neste mesmo viés, faremos uma analise sobre as políticas desenvolvida pelo governo do Estado do Rio Grande do Sul no campo educativo sobretudo, o da EJA. Ainda no que concerne esta modalidade, é fundamental dialogar sobre a resolução ${ }^{\circ} 343$ de 11 de abril de 2018 do Conselho Estadual de Educação do Estado do Rio Grande Sul que trata da consolidação das normas relativas à oferta da EJA no sistema estadual de ensino como também, define providência para garantir o acesso e a permanências destes sujeitos com defasagem idade/série. Por fim, em uma sociedade classista e desigual, onde a educação institucionalizada possui sérios problemas recorrentes como a falta de investimentos, se faz necessário que nesses espaços os educadores e educadoras tenham a dimensão da importância que é articular uma educação com valores progressistas e humanitários.
\end{abstract}

Palavras-Chave: Educação de Jovens e Adultos; educação Popular; Políticas Públicas; Esperança.

\section{Resumen}

Este estudio trae un recorte de la Disertación "El Horizonte de la Educación de Jóvenes y Adultos Mientras Instrumento de Emancipación de la Clase Trabajadora: Reflexiones sobre Educación Trabajo y Enseñanza Media" y tiene como propósito dialogar sobre la Educación de Jóvenes y Adultos - EJA, como una modalidad importante en lo que se refiere a la democratización y el derecho a la educación. Consciente de que nuestra sociedad viene caminando en contra de la lucha contra las desigualdades sociales, principalmente en lo que se refiere a la oferta de la enseñanza de EJA y las políticas de permanencia. En este sentido, buscamos hacer una investigación sobre el escenario de la EJA en el municipio de Rio Grande y las políticas públicas establecidas. Resaltamos que en este mismo sesgo, haremos un análisis sobre las políticas desarrolladas por el gobierno del

\footnotetext{
${ }^{1}$ Mestre em Educação; Universidade Federal do Rio Grande - FURG; Rio Grande, Rio Grande do Sul, Brasil; daiane.ferreira13@outlook.com

${ }^{2}$ Doutora em Engenharia de Produção; Universidade Federal do Rio Grande - FURG; Rio Grande, Rio Grande do Sul, Brasil; elainepereira@ prolic.furg.br

${ }^{3}$ Doutor em Filosofia da Educação pela Universidade federal do Rio Grande do Sul- UFRGS; Rio Grande; Rio Grande do Sul; Brasil; vilmar1972@gmail.com
} 
Estado de Rio Grande do Sul en el campo educativo sobre todo, el de la EJA. En lo que concierne a esta modalidad, es fundamental dialogar sobre la resolución n ${ }^{\circ} 343$ de 11 de abril de 2018 del Consejo Estatal de Educación del Estado de Rio Grande Sul que trata de la consolidación de las normas relativas a la oferta de la EJA en el sistema estadual de enseñanza, , define la providencia para garantizar el acceso y la permanencia de estos sujetos con desfase edad / serie. Por último, en una sociedad clasista y desigual, donde la educación institucionalizada tiene serios problemas recurrentes como la falta de inversiones, se hace necesario que en esos espacios los educadores y educadoras tengan la dimensión de la importancia que es articular una educación con valores progresistas y humanitarios.

Palabras claves: Educación de Jóvenes y Adultos; educación popular; Políticas públicas; esperanza

\begin{abstract}
This study brings a cut of the Dissertation "The Horizon of Youth and Adult Education as an Instrument of Emancipation of the Working Class: Reflections on Work and Secondary Education" and the purpose of this study is to discuss the education for youth and adult people (EJA) as an important modality in terms of democratization and the right to education. Aware that, our society has been moving against the social inequalities, especially with regard to the provision of EJA teaching and policies of permanence. In this sense, we seek to do a research on the scenario of the EJA in the municipality of Rio Grande and the established public policies. We emphasize that we will make an analysis on the policies developed by the government of the State of Rio Grande do Sul in the educational field, especially the EJA. Still, with regard to this modality, it is fundamental to discuss the resolution $n^{\circ} 343$ of April 11, 2018 of the State Council of Education of the State of Rio Grande Sul, which deals with the consolidation of the rules regarding the EJA offer in the state education system as well as, defines a measure to guarantee the access and permanence of these subjects with age / series discrepancy. Finally, in a classy and unequal society where institutionalized education has serious recurring problems such as lack of investment, it is necessary that in these spaces educators have the dimension of the importance of articulating an education with progressive and humanitarian values.
\end{abstract}

Keywords: Youth and Adult Education; Popular education; Public policy; Hope.

\title{
1. Introdução
}

A Educação de Jovens e Adultos (EJA) vem passando por muitas mudanças, tanto no que se refere às legislações, como também no que concerne o campo teórico desta modalidade. Escrever sobre a EJA hoje é primordial dialogar sobre o cenário de disputa, de luta e resistência que ao longo da história fez parte de sua constituição. É um campo onde a diversidade se faz presente, onde diferentes protagonistas lutaram e lutam por uma educação mais igual e justa.

Estamos caminhando durante anos na luta por direitos à educação para todos e todas, políticas de permanência e ampliação de vagas em todos os níveis de ensino, no entanto, o movimento que os governos têm feito, corresponde a cortes e congelamentos nos investimentos, tanto no área da saúde, educação, segurança dentre outros. Na contra marcha desta realidade, busca-se articular a EJA e o campo teórico desta modalidade com as concepções da Educação Popular, pois segundo Freire (2015, p.33) "a educação de adultos é mais bem percebida quando a situamos hoje como Educação Popular", com a intencionalidade de subverte a lógica da educação bancária. 
Através dessas concepções, entendemos que para enfrentar o estado hegemônico é preciso ter um trabalho, como Freire já mencionava, de conscientização do sujeito. Dito isso, é necessário investir em políticas públicas, sobre tudo na EJA, pois ainda possuímos dados significativos no que tange o analfabetismo e jovens que abandonam a escola e interrompem sua formação. Não diminuiremos as desigualdades e injustiças sociais enquanto houver homens, mulheres, crianças, jovens e idosos sem o direito de acesso e permanência em uma escola com um ensino de qualidade. Para compreender sobre o campo deste estudo é fundamental dialogar sobre as políticas públicas da EJA implementadas no estado do Rio Grande do sul e no Município do Rio Grande, sendo este nosso principal campo de pesquisa.

\section{Os Caminhos da Educação de Jovens e Adultos Trilhados no Estado do Rio Grande do Sul}

A Educação de Jovens e Adultos demarcou seu espaço no Estado do Rio Grande do Sul. Nesse sentindo, lembrar da EJA neste contexto é refletir sobre um dos mais importantes Movimentos Nacionais de Alfabetização, denominado de MOVA - Movimento de Alfabetização de Jovens e Adultos. O MOVA Brasil começou a ser concretizado em 2003, iniciando suas atividades na região com o maior índice de analfabetismo do Brasil que é o Nordeste, tendo então como meta alfabetizar mais de 40 mil educandos e educandas em três anos e meio. O MOVA no Rio Grande do Sul teve seu início no ano de 1999, segundo BARRETO (2003, p.55):

O MOVA-RS é um Movimento de Alfabetização de pessoas Jovens e Adultas, pioneira, enquanto uma ação de caráter estadual, com princípios políticos voltados à construção de uma prática popular que rompe com a idéia de campanha, especialmente sob seus ideais: assistencialistas, mercantis, compensatórios e com preocupações pedagógicas alheias aos interesses do alfabetizando.

A caminhada da EJA no Rio Grande do Sul não se resume ao projeto MOVA, no entanto, o MOVA foi um dos projetos mais importantes, pois tinha na sua construção e organização um olhar diferenciado para os jovens e adultos que constituem esta modalidade. Antes de 1999, outros projetos de alfabetização também fizeram parte da história da EJA no Rio Grande do Sul, um deles foi o projeto LER - Ler e Escrever o Rio Grande, que teve seu início em 1986 e era coordenado pela Secretaria Estadual da Educação. Sem muitos incentivos e com o objetivo de alfabetizar, em massa, jovens e adultos, o projeto LER se manteve por alguns anos e, paralelo a ele, em 1991, a Secretaria Estadual da Educação lançou o projeto denominado Nenhum Adulto Analfabeto. De acordo com Kaerfer (2009, p.45): 
O programa estava organizado por módulos, feitos por uma equipe multidisciplinar, que se encarregou de organizar o material didático dividido em dez módulos, nos quais se encontravam subsídios pedagógicos para a alfabetização. Era de fato uma tentativa não formal de alfabetização, onde qualquer cidadão que tivesse interesse e boa vontade poderia alfabetizar alguma turma de alunos, teria acesso a esses módulos. Não havendo o vínculo pedagógico nem responsabilidade de recursos financeiros para com o educador que dispunha a alfabetizar.

Logo, constituiu-se um projeto com a tentativa de alfabetização não formal, mas que, ao mesmo tempo, desvalorizava o educador, pois o Estado não se responsabilizava com a formação destes e tampouco dispunha de recursos financeiros para subsidiar o trabalho. Entre os anos de 1995 a 1998, surge outro projeto de alfabetização, denominado de Pacto por um Rio Grande Alfabetizado - PÍA 2000, muito semelhante ao projeto LER. De acordo com a Kaerfer (2009, p.46):

Foram 45 municípios contemplados com essa proposta, onde os educadores eram chamados de educadores da alfabetização, não era obrigatoriedade ter titulação de professor, devido à difícil realidade dos municípios. Efetivou-se através de convênios com as prefeituras com repasse de recursos para kit pedagógico e ajuda de custo para os educadores. [...] contemplava a formação deste educadores que eram dadas pelas universidades e/ou agentes formadores da região ou do município.

Os programas criados antes do MOVA tinham um objetivo claro que era a alfabetização em massa. Entretanto, nesses projetos, o que podemos observar é um distanciamento com o contexto desses jovens e adultos e a não valorização dos educadores e educadoras. Por outro lado, o MOVA, tinha como referência no currículo da EJA a Educação Popular. Assim, nesse período, os projetos de alfabetização tinham uma relação forte com as questões sociais, econômicas e culturais, fazendo com que o MOVA se tornasse um dos maiores movimentos de alfabetização, o que culminou na criação de mais de trinta Núcleos de Educação de Jovens e Adultos.

Outro momento no cenário político do Estado ocorre no a partir de 2002, com a mudança de governo que apresentava como prioridades as áreas que possuíam maior carência social. No que tange a Educação de Jovens e Adultos, esse período buscou "implementar projetos de alfabetização e ofertar cursos no ensino Fundamental e Médio" (KAEFER, 2009, p.79).

No ano de 2006 um novo governo assume o Estado do Rio Grande do Sul, com uma roupagem de campanha política no viés da "política nova", utiliza em sua campanha o slogan: "Um Jeito Novo de Governar". No entanto, embora o slogan apresentasse a lógica de uma "nova forma de governar", o que podemos observar é que no que tange a educação o governo foi tão ou mais neoliberal que o seu antecessor. Segundo Kaerfer (2009, p.90): 
As noticias vinculadas pela mídia mostra que este governo optou por uma política de "enturmação" dos educandos e otimização dos recursos humanos. Para 2008 a Secretaria Estadual de Educação (SEC) anunciou o fechamento de 153 turmar por falta de demandas, afetando cerca de 7 mil estudantes.

Na educação de jovens e adultos não foi diferente, pois as Coordenadorias regionais ficaram com a incumbência de fazer o levantamento dos educandos e educandas matriculados nesta modalidade e as turmas que possuíam pouca frequiência destes eram fechadas e os que permaneciam na EJA eram realocados para outras turmas ou até outras escolas.

No ano de 2010 o desafio era (re) organizar as políticas públicas e reverter às políticas de desmantelamento implementadas pelos governos anteriores. No entanto, muda-se a forma de pensar a EJA no Estado, mas o que se observou na realidade é que a linha neoliberal se manteve principalmente no que tange esta modalidade. Em 2014 assume um novo Governador do Estado. Período que ficou marcado pelo parcelamento dos salários dos servidores públicos estaduais, sobre tudo os da educação, o fechamento de turmas dos diferentes níveis da formação básica e também o fechamento de escolas, além do sucateamento das mesmas. Este governo ficou marcado pelo não diálogo com os trabalhadores da educação, pelo desmantelamento e precarização da educação no Estado, culminando em uma das maiores greves da categoria. No segundo semestre de 2017, o Governo estimava um fechamento de mais de 2 mil turmas.

Diante dos desmontes que ocorrem na EJA e como este cenário vem sendo produzido no estado do Rio Grande do Sul o Conselho Estadual de Educação lançou a Resolução N ${ }^{\circ}$ 343, de 11 de Abril de 2018 que apresenta normas relativas à oferta da EJA no sistema estadual de Ensino como também apresenta providências na garantia de acesso e permanência de adolescentes e jovens com defasagem idade/etapa escolar.

Deste modo, diante desta organização histórica sobre as mudanças e políticas públicas da educação realizadas por diferentes governos no Estado do Rio Grande do Sul, fica evidente que ainda há muito a ser feito pela EJA. Ainda há um olhar carregado de preconceitos que envolvem esta modalidade, e com isso uma desvalorização que culmina em uma desigualdade social e a não construção de espaços que contribuam com a formação de jovens e adultos. Os movimentos em prol de uma educação de qualidade para todos e todas ainda lutam pela valorização e investimentos na EJA, sobre tudo, na formação dos educadores e educadoras que atuam nesse contexto.

\subsection{Os Caminhos da Educação de Jovens e Adultos Trilhados no Município do Rio Grande}


A EJA possui em sua história uma ligação direta com os movimentos sociais e sua vertente na luta pelos direitos, sobretudo da classe trabalhadora. Nesse contexto, a EJA teve início na cidade em 1990, com o Projeto de Alfabetização Alicerce Municipal de Educação de Jovens e Adultos (ALMEJA), na escola de Ensino Fundamental Helena Small. Com a extinção do ALMEJA, em 2000, foi criado a Educação de Jovens e Adultos (PROMEJA). De acordo com Miranda:

O programa tinha por objetivo suprir a necessidade de escolarização de jovens e adultos que não concluíram o Ensino Fundamental na idade própria. A proposta considerava o contexto sócio-político desta população e o desafio de fortalecer sua participação na construção de uma sociedade igualitária, resgatando a cidadania e a auto-estima (RIO GRANDE, 2000, p. 05 IN MIRANDA, 2013, p. 53).

Mesmo que o PROMEJA não fosse ofertado em todas as escolas municipais, pela primeira vez um programa de Educação de Jovens e Adultos se inseria em uma comunidade da zona rural, conforme Miranda (2013, p.66):

Na zona rural, apenas na Ilha da Torotama, foram ofertadas turmas do PROMEJA. No período entre 2002 a 2005, ocorriam em turno vespertino, das 16h às 20h, na E.M.E.F. Cristóvão Pereira de Abreu. Conforme a direção da escola, as turmas foram extintas, diante da falta de público interessado.

O programa antes denominado de PROMEJA, em 2013 passa a se chamar Educação de Jovens e Adultos, distribuído em 13 Escolas Municipais. Além disso, o município dispõe ainda de mais 11 escolas da rede estadual que ofertam a modalidade da EJA e um Núcleo Estadual de Educação de Jovens e Adultos (NEEJA), ambos coordenados pela $18^{\mathrm{a}}$ Coordenadoria Estadual de Educação.

Em 2013, é lançado o projeto “Olhares Sul-Rio-Grandeses na Formação Continuada de Jovens e Adultos", no município do Rio Grande. Um projeto financiado pelo Ministério da Educação e alocado na Secretaria de Educação Continuada, Alfabetização, Diversidade e Inclusão (SECADI). O projeto Olhares, assim chamado pelos tutores, cursistas, colaboradores e parceiros, tinha um envolvimento com os profissionais da Educação Básica e como parceiros a Secretaria de Município da Educação do Rio Grande e da $18^{\text {a }}$ Coordenadoria Regional de Educação do Estado do Rio Grande Sul, atuando não só no município do Rio Grande, como também, em São José do Norte, Santa Vitória e Chuí. Esse projeto teve uma grande importância, pois envolveu educadores e educadoras de vários municípios com um único propósito: que fossem ouvidas as demandas desse setor e que, juntos, pudessem dialogar sobre as principais problemáticas, angústias e inseguranças que estes profissionais sentiam no seu dia a dia em sala de aula. 
Historicamente, a EJA carece de investimentos na formação de educadores e educadoras da área em material, em espaço físico para lecionar, bibliotecas, enfim, uma serie de demandas que, ao longo da história, vão se acumulando sem perspectiva de resolução. Ainda carecemos de políticas públicas educacionais que pensem na diversidade cultural, étnico-raciais, no sujeito do campo, nos homens e mulheres, jovens e adultos, pertencentes ou não de comunidades tradicionais ${ }^{4}$, que constituem a modalidade da EJA. Nas palavras de Gadotti (2013, p.26):

A diversidade pode ser considerada como uma grande riqueza, mas a desigualdade social e econômica é a nossa pobreza maior. O mapa do analfabetismo é o mesmo da pobreza, onde falta tudo, não só o acesso a educação. Por isso, a luta pelo direito à educação não está separada da luta pelos demais direitos. E não basta oferecer um programa de educação de adultos. É preciso oferecer condições de aprendizagem, transporte, locais adequados, materiais apropriados, muita convivência e também bolsas de estudos.

Diante deste cenário, acreditamos ser de profunda importância abordar sobre um projeto que fez história nos contextos onde se inseriu. Trata-se do Projeto Educação para Pescadores, conhecido, talvez, em todo o pai e que iniciou em 2008, na comunidade da Ilha da Torotama, e atuou nas comunidades da Zona Rural do Município do Rio Grande. O Projeto surgiu devido a uma demanda das comunidades pesqueira que era a conclusão da formação básica e com isso proporcionou a formação no ensino fundamental e médio para centenas de homens e mulheres. Sujeitos esses que mesmo a legislação garantindo o direito a educação para todos, ainda não existe a modalidade da EJA nas comunidades onde moram. O projeto, foi um importante mediador no que se refere a formação básica para sujeitos com defasagem idade/série e além disso, reforça que, na atualidade, ainda contamos com projetos para dar conta desta dívida histórica no campo da EJA.

Os projetos e programas no campo da educação são importantes para responder a uma demanda reprimida, mas se faz necessário a implementação de políticas públicas para que ações como essas sejam permanentes e não por determinado tempo. Neste viés, baseado na organização do Educação Para pescadores, surge no Município do Rio Grande uma Escola Municipal de Educação de Jovens e Adultos denominada Paulo Freire. Conhecida Como EMEJA Paulo Freire, esta escola surge não só das demandas existentes no município, mais

\footnotetext{
${ }^{4}$ Ver Decreto 6.040, de 7 de Fevereiro de 2007, que Institui a Política Nacional de Desenvolvimento Sustentável dos Povos e Comunidades Tradicionais. Disponível em: <http://www.planalto.gov.br/ccivil_03/_ato20072010/2007/decreto/d6040.htm>. Acesso em: 19 jan. 2017.
} 
também como um política pública de resistência no campo da EJA. Para elem disso, está escola possuí ainda outro diferencial que se torna fundamental no que tange ao direito de escolarização de todas e todos cidadãos, pois ela é um modelo de escola itinerante que vai até as comunidades que há demandas. Isso, além de valorizar o contex to do sujeito corrobora para uma menor índice de abandono do processo formativo. Atualmente a EMEJA Paulo Freire está atuando em duas comunidades do município do Rio Grande. Estas comunidades ficam distantes do centro urbano do município, onde a maioria dos educandos e educandas são adultos trabalhadores.

O município do Rio Grande avança na história da EJA, pois a EMEJA Paulo Freire é demarca um momento de esperança no que tange a educação pública. Um marco sobretudo no que concerne a resistência e valorização da modalidade da EJA. Não há combate as desigualdades e injustiças sociais se não houver escolas com educação de qualidade para todas e todos, pois a educação é uma ferramenta importante na construção de uma sociedade humanizadora, solidaria e livre de preconceitos. De acordo com Freire (2000, p. 31) "se a educação sozinha não transforma a sociedade, sem ela tampouco a sociedade muda".

\section{Educação de Jovens e Adultos em um Cenário de Mudança: entre a indignação e a esperança.}

O processo de desqualificação da educação pública atinge diretamente a Educação de Jovens e Adultos. Se a EJA sempre foi tratada com discriminação e em nenhum momento se pensou uma política pública que contemplasse a diversidade presente nesta modalidade, agora a situação ficará ainda pior, pois a EJA é uma das modalidades que recebe menos investimentos e com os cortes que vem ocorrendo no setor da educação, em âmbito geral, não podemos esperar que ocorra o inverso do que já é realidade. Nas palavras de Arroyo (2006, p.221)

Nela se cruzaram e cruzam interesses menos consensuais do que na educação da infância e da adolescência, sobretudo quando os jovens e adultos são trabalhadores, pobres, negros, subempregados, oprimidos, excluídos. O tema nos remete à memória das últimas quatro décadas e nos chama para o presente: a realidade dos jovens e adultos excluídos.

O que não podemos deixar de refletir, neste trabalho, é que todo esse movimento de redução de direitos e aniquilação da educação tem um propósito muito devasso que é fazer com que as classes populares continuem sendo subalternas da burguesia, sendo meros coadjuvantes desta história. Para combater isso, a EJA é uma mediadora fundamental no que 
tange a democratização e o direito a educação. Ressaltamos que a EJA possui imbricada na sua trajetória a relação intrínseca com a Educação Popular.

A educação popular não é nem um nível de educação ou uma modalidade, mas é uma pedagogia antagônica, que subverte a lógica da educação bancária. Falar sobre a Educação Popular, neste modo, é falar sobre as pedagogias de Paulo Freire. Pedagogias estas que dialogam com os diferentes, os pobres, negros, quilombolas, indígenas, ou seja, dialoga com o povo, com o povo plural, que ainda luta por uma educação justa e igualitária. A Educação Popular é uma concepção de educação e segundo Zitkoskis (2011, p. 14):

Como concepção de educação, contrapõe-se às concepções hegemônicas e vai sendo construída no acúmulo de experiências de organização das classes populares e nas lutas travadas por ela na busca de libertação do sistema opressor.

A Educação Popular tem um forte envolvimento com a classe trabalhadora e popular. Paulo Freire foi um idealizador da Educação Popular e que acreditou que o povo era capaz de se libertar da alienação, de se conscientizar politicamente, culturalmente e acreditava na emancipação social das classes oprimidas e excluídas. Como educador comprometido com uma educação emancipadora, via no diálogo uma forma de construir uma educação mais esperançosa e propositiva. Para Zitkoski:

O diálogo é a força que impulsiona o pensar crítico-problematizador em relação à condição humana no mundo. Através do diálogo podemos dizer o mundo segundo o nosso modo de ver. Além disso, o diálogo implica uma práxis social, que é o compromisso entre a palavra dita e a nossa ação humanizadora (2016, p. 117)

É preciso formar sujeitos com condições de ler o mundo de maneira mais crítica e que sejam atuantes nas mudanças sociais. Assim, Freire (1989, p.15) nos diz que a conscientização está alinhada com a práxis.
A conscientização não pode existir fora da "práxis", ou melhor, sem o ato ação - reflexão. Esta unidade dialética constitui, de maneira permanente, o modo de ser ou de transformar o mundo que caracteriza os homens. Por isso mesmo, a conscientização é um compromisso histórico. É também consciência histórica: é inserção crítica na história, implica que os homens assumam o papel de sujeitos que fazem e refazem o mundo.

Em uma sociedade classista e desigual, onde a educação institucionalizada possui sérios problemas recorrentes como a falta de investimentos, se faz necessário que nesses espaços os educadores e educadoras tenham a dimensão da importância que é pensar e praticar uma educação com valores progressistas e humanitários. Não podemos deixar de ressaltar aqui que de um modo geral a EJA não conseguiu criar enraizamento nos sistemas públicos, isso porque segundo Paiva (2005, p.542, grifo da autora) "a história da EJA no Brasil foi constituída como uma história de experiências". 
Nesse sentido, pensar na educação como instrumento político e de conscientização se dará pelas práticas e pedagogias que dialoguem com a Educação Popular. Para enfrentar o estado hegemônico é preciso ter um trabalho, como Freire já mencionava, de conscientização do sujeito. Isso acontecerá apenas quando os educadores pensarem na educação como um meio de libertação, fazendo dela um ato criador, portanto, os educadores (as) precisam ter uma consciência histórica. Para Gadotti (2006, p.159):

A cultura escolar dos sistemas de ensino é, em geral, essencialmente anti-popular. Dessa forma, dificilmente mudará a partir de dentro. Daí a importância e o papel [...] dos movimentos sociais e populares e dos partidos do campo democrático na busca de alternativas concretas que influenciem a abertura dos sistemas de ensino. Ela tem um papel importante principalmente na mudança de caráter da escola, de onde pode partir a reestruturação curricular e a mudança de mentalidade.

Toda educação é política, ou seja, não existe neutralidade, o que existem são princípios e valores acerca de uma visão de mundo e sociedade. A Educação Popular é o oposto da educação que conhecemos na maioria dos espaços de educação formal, onde a postura do educador por muitas vezes é autoritária ou ainda segue um viés de educação domesticadora, sem apresentar uma educação democrática. Mais do que isso, a educação Popular é antagônica a educação bancária que percebe o sujeito apenas como depósito do saber.

Em um contexto onde a diversidade é o que predomina em sala de aula, e isso acontece em todos os espaços formais, afinal nós não somos sujeitos iguais, somos sujeitos carregados de saberes diferentes, de visões de mundo diferentes, somos fruto do acúmulo das nossas experiências, então não podemos estar de acordo com uma educação formal que busca, a todo o momento, padronizar seus educandos e educandas, corroborando para o processo de exclusão típico do nosso sistema educacional. Lembrando Gramsci (1978, p.136):

É sempre bom ter claro que as escolas são antidemocráticas não pelos conteúdos que ensinam - acadêmicos, "desinteressados", ou técnico-profissionalizantes, "interessados" -, mas por sua função, a de preparar diferentemente os intelectuais segundo o lugar que irão ocupar na sociedade, e portanto, segundo sua origem de classe, como dirigentes ou como trabalhadores.

O educador ou educadora popular precisa saber e compreender as relações que se estabelecem no contexto em que está atuando e, na busca de tornar o processo de aprendizagem significativo e comprometido com o cidadão social, é preciso refletir sobre as injustiças, é preciso compreender essa diversidade. Nesse sentido, Gadotti (2012, p.11) nos apresenta uma perspectiva utópica da educação a ser seguido:

Creio que o verdadeiro realismo do educador popular, social e comunitário é a utopia, porque esse educador educa em função de um sonho na busca de um mundo justo, produtivo e sustentável para todos e todas. Para intervir e mudar o mundo que 
deseja transformar, ele precisa conhecer a realidade onde atua, com os pés no chão, mas procurando enxergar longe.

Nesse sentido, a não valorização da Educação de Jovens e Adultos, a falta de recursos destinados a esta modalidade, bem como a falta de formação para os educadores e educadoras desta área, corrobora para que este cenário de desvalorização se mantenha e continue produzindo em larga escala as desigualdades sociais. Assim, a não valorização da EJA faz com que estes sujeitos, jovens e adultos sejam duplamente penalizados, primeiro porque não concluíram a sua formação na "idade certa", depois porque quando o sujeito procura um espaço para terminar sua formação através da EJA, muitas vezes, esses espaços negam a diversidade desses sujeitos, colaborando para a não adaptação deste adulto à realidade da escola, negando pela segunda vez o seu direito à formação.

A EJA representa o reconhecimento do cometimento de uma grave injustiça, um direito negado, de todo esse histórico dos sujeitos que a constitui e por isso ela não tem que ser compensatória, ele precisa ser cidadã. Para Arroyo (2006, p.223):

\footnotetext{
A educação popular, a EJA e os princípios e as concepções que as inspiraram na década de sessenta continuam tão atuais em tempos de exclusão, miséria, desemprego, luta pela terra, pelo teto, pelo trabalho, pela vida. Tão atuais que não perderam sua radicalidade, porque a realidade vivida pelos jovens e adultos populares continua radicalmente excludente.
}

Nessa perspectiva de uma EJA cidadã, olhamos para este horizonte através da EMEJA Paulo Freire, que embora tenha menos de um ano atuando nas comunidades, possui um engajamento com a Educação Popular. Com isso, a valorização e a construção das aprendizagens acontecem de forma dialógica e na horizontalidade, respeitando os saberes que cada sujeito traz das suas vivências. Nesse viés, percebemos a EMEJA Paulo Freire como um espaço de esperança, mas não a esperança como "pura espera", mais uma esperança que se renova com a possibilidade de criar um outro futuro, Freire (2015).

Na contramarcha da realidade, onde o que observamos é o fechamento de escolas públicas, extinção de turmas de todos os níveis, sobre tudo da EJA, a EMEJA Paulo Freire nasce na perspectiva da valorização do sujeito e de seu contexto e não como mais um espaço para a formação aligeirada ou ainda em um viés compensatório. São políticas públicas como essa que fortalecem os movimentos sociais, sindicatos e tantos outros espaços que lutam pela educação pública de qualidade. Pois é investindo na educação pública, garantindo o acesso e permanência de cada um e cada uma nas escolas, que conseguiremos combater as injustiças sociais.

\section{Conclusões}


Cada vez mais se faz necessário pensar uma política articulada de educação de jovens e adultos que caminhe junto e dialogue com a Educação Popular. É preciso reconhecer e legitimar o conhecimento que existe nas comunidades e que é compartilhado pelos sujeitos que ali estão, pensando neste saber popular, da cultura, das crenças que um povo traz em si. É esse saber popular juntamente com o saber científico que dará sentido ao processo de formação dos educandos e educandas da EJA, que nem sempre procuram essa modalidade de ensino para resgatarem sua condição de educandos (as) por estarem "atrasados" na concepção temporal cronológica de seus estudos. Por vezes a EJA é a única saída para viabilizar a continuidade da formação para uma grande massa de jovens trabalhadores.

É evidente que a EJA é percebida como uma modalidade compensatória, desconsiderando o processo histórico do sujeito. Assim, sabemos que é possível trabalhar com a EJA a partir de uma concepção da Educação Popular, no entanto, essa práxis terá que partir do educador e da educadora, pois sabemos que não existe a possibilidade de ser decretada uma estrutura curricular baseada nas orientações da Educação Popular.

É preciso pensar uma Política de Educação de Jovens e Adultos que seja engajada com os Estados e Municípios, que dialogue e construa de forma conjunta com os movimentos de alfabetização e EJA que tem por todo o país, contando com a parceria de ONG's, sindicatos, núcleos educacionais, a sociedade civil, os movimentos sociais, os educadores e educadoras, pois é preciso ouvir todos (as) e construir com todos (as), baseados e alicerçados na Educação Popular.

Desse modo, pensar que é possível uma mudança revolucionária na sociedade é acreditar que, em algum momento (e que seja em breve), os governos comecem a respeitar e investir na educação como ela merece. É investir em educação pública e que esta seja de qualidade, pois a educação é um direito de todos e todas. Se continuarmos caminhando na contramão e fazendo da educação mais um espaço de negócios com os senhores do Capitalismo, estaremos fadados ao fracasso e ampliando estes índices de desigualdades sociais.

\section{Referências}

ARROYO. Miguel. A educação de jovens e adultos em tempos de exclusão. In: Construção coletiva: contribuições à educação de jovens e adultos. Brasília:

UNESCO, MEC, RAAAB, 2006.

BARRETO, Sabrina das Neves. O processo de alfabetização na MOVA RS: narrativas e significados na vida das mulheres. 2005. Dissertação (Mestrado em Educação) - Programa de Pós-Graduação em Educação, Fundação Universidade do Rio Grande, Rio Grande, 2005. 
FREIRE, Paulo. Conscientização - teoria e prática da libertação: uma introdução ao pensamento de Paulo Freire. São Paulo: Cortez e Moraez, 1989.

. Política e educação. [organização Ana Maria de Araujo Freire]. 2aed. - São Paulo: Paz e Terra, 2015

Pedagogia da Indignação: cartas pedagógicas e outros escritos. $1^{\text {a }}$ Ed. - São Paulo: Paz e Terra, 2014.

Pedagogia da Esperança: um reencontro com a pedagogia do oprimido. $22^{\mathrm{a}}$ ed. São Paulo: Paz e Terra, 2015.

GADOTTI, Moacir. Educação Popular na América Latina Aspectos Históricos e Perspectivas. REXE - Revista de Estudios y Experiencias em Educación. UCSC, n9, 2006.

Educação popular, educação social, educação comunitária. Conceitos e práticas diversas, cimentadas por uma causa comum. Revista Dialogos: pesquisa em extensão universitária. IV Congresso Internacional de Pedagogia Social: domínio epistemológico. Brasília, v.18, n.1, dez, 2012.Disponível:https://portalrevistas.ucb.br/index.php/RDL/article/viewFile/3909/2386

2013

Educação de Adultos Como direito. EJA em Debate, Florianópolis,Ano 2, n.2. jul.

GRAMSCI, A. Os Intelectuais e a Organização da Cultura. Trad.de Carlos Neto Coutinho. Rio de Janeiro: Civilização Brasileira, 1982.

KAEFER, Maria Terezinha. Da intenção a ação: avanços e retrocessos da educação de jovens e adultos na rede estadual do RS no período de 1999 a 2008. 2009. Dissertação (Mestrado em Educação) - Programa de Pós-Graduação em Educação, Universidade Federal do Rio Grande do Sul, Porto Alegre, 2009.

MIRANDA, Sicero Agostinho. Os saberes matemáticos no cotidiano dos Pescadores Artesanais das Comunidades Tradicionais de Pesca da Cidade de Rio Grande. 2014. Qualificação (Mestrado em Educação) - Universidade Federal do Rio Grande - FURG, Rio Grande, 2014.

PAIVA, Jane. Educação de jovens e adultos: direito, concepções e sentidos. Tese (doutorado), Universidade Federal Fluminense - Rio de Janeiro, 2005.

ZITKOSKI, Jaime José; MORIGI, Valter (org). Educação Popular e práticas emancipatórias: desafios contemporâneos. Porto Alegre: Companhia Rio-grandense de Artes Gráficas (CORAG), 2011. 